Religiosidad y experiencias emocionales sobre aborto

Relatos de mujeres sobre culpas, castigos y procesos de resignificación

Natalia Santarelli, Claudia Anzorena

Con X (N. ${ }^{\circ}$ ), e037, 2021

ISSN 2469-0333 | https://doi.org/10.24215/24690333e037

http://perio.unlp.edu.ar/ojs/index.php/conequis

FPyCS | Universidad Nacional de La Plata

La Plata | Buenos Aires | Argentina

\title{
Religiosidad y experiencias emocionales sobre aborto
}

\author{
Religiosity and Emotional Experiences of Abortion
}

\author{
Natalia Santarelli ${ }^{12}$ Claudia Anzorena ${ }^{13}$ \\ m.natalia.santarelli@gmail.com claudia_anzorena@yahoo.com.ar \\ https://orcid.org/0000-0002-6628-4670 https://orcid.org/0000-0003-3074-2278 \\ 1 Consejo Nacional de Investigaciones Científicas y Técnicas (CONICET) \\ 2 Universidad Nacional de San Luis \\ 3 Instituto de Ciencias Humanas, Sociales y Ambientales (INCIHUSA) \\ del Centro Científico Tecnológico (CCT) Mendoza \\ Argentina
}

\section{Resumen}

Desde un enfoque biográfico, las autoras exploran los interjuegos entre religiosidad y experiencias de aborto de mujeres que al momento de abortar se autodefinieron como creyentes de religiones, y reflexionan sobre las articulaciones entre estas creencias y las experiencias emocionales en escenarios sociosubjetivos donde la criminalización, los discursos de género hegemónicos y los feministas aportan sentidos y resignifican dichas experiencias de maneras diversas y cambiantes.

Palabras clave | aborto, religiosidad, experiencias de mujeres, género

\section{Abstract}

From a biographical approach, the authoress explores the interplay between religiousness and abortion experiences of women who self-defined as religious believers at the time of their abortion, and reflects on the articulations between religious beliefs and emotional experiences in socio-subjective scenarios where the criminalization and both hegemonic and feminist gender discourses provide meanings and resignify said experiences in diverse and changing ways.

Keywords | abortion, religiousness, women's experiences, gender 


\title{
Religiosidad y experiencias emocionales sobre aborto
}

\author{
Relatos de mujeres sobre culpas,
} castigos y procesos de resignificación

Por Natalia Santarelli y Claudia Anzorena

Las experiencias de aborto son complejas, multideterminadas, heterogéneas, dinámicas y situadas. Se inscriben de formas singulares en un momento específico de cada trayectoria vital de la mujer o de la persona gestante que aborta. A la vez que ocurre en la intersección de determinadas relaciones sociales de poder: de género, económicas, legales y culturales comunes (Sanseviero, 2003).

Las significaciones que se construyen sobre la propia experiencia se expresan mediante los recuerdos, que adquieren mayor intensidad, se entretejen y se dejan ver en los relatos (Carril Berro \& López Gómez, 2008). En términos de Ana María Fernández y de Débora Tajer (2006), las significaciones son la compleja configuración subjetiva que se produce en torno a la práctica abortiva, en la que juegan un rol decisivo el bagaje de significaciones sociales dominantes y lo que cada mujer -o persona gestante- componga acerca de lo legal y de lo legítimo de esa decisión. A su vez, las significaciones y los sentidos sobre la práctica se asocian a determinadas vivencias emocionales que contemplan desde el malestar psíquico hasta el alivio y el bienestar emocional. Dichas significaciones y emocionalidades pueden coexistir, conflictuarse, intensificarse, resignificarse y/o transformarse en el marco de cada experiencia. 
Este artículo $^{1}$ forma parte de una investigación cualitativa con perspectiva de género feminista, que utiliza el método biográfico para abordar algunas relaciones entre las significaciones que las mujeres construyen sobre sus experiencias de aborto voluntario farmacológico clandestinizado y las condiciones de preservación, de producción y de afectación de la salud mental. Dentro de los diversos organizadores de sentidos presentes en las experiencias relatadas, surge un aspecto que adquiere un carácter singular y sobre el que ahondaremos en este escrito: la religiosidad de mujeres que al momento de abortar se autopercibían como creyentes y/o practicantes.

A partir del análisis de relatos de mujeres que han abortado en zonas urbanas de las provincias de Mendoza y de San Luis, Argentina, se focaliza en el papel que jugaron las creencias religiosas y la visión de dios en la construcción de determinadas significaciones y emocionalidades en torno a las propias experiencias de aborto. Asimismo, abordaremos algunos procesos de resignificación de los malestares y las culpas en torno a la experiencia, cuando estos estuvieron presentes.

Consideramos que ahondar en estos relatos desde una perspectiva feminista contribuye a la construcción de unos sentidos otros para el acompañamiento -activista y/o profesional- de las experiencias de aborto en contextos de ilegalidad y en vistas a su transformación.

\section{Significaciones hegemónicas sobre sexualidad y aborto:}

el interjuego entre lo religioso, lo legal y los mandatos de género

Las religiones institucionalizadas en Occidente tienen un fuerte peso en la construcción de discursos de verdad, cuya dimensión productiva vehiculiza ciertas nociones de sujeto que operan de forma efectiva en un determinado tiempo y espacio: someten los cuerpos, regulan los comportamientos (Foucault, 1979) y/o generan emocionalidades afines a las verdades que pretenden imponer. $\mathrm{Su}$ influencia a nivel macro y micro político se entrama en diversos niveles sociosubjetivos de las experiencias humanas, particulares y colectivas.

En cuanto a la dimensión moral, los preceptos y las enseñanzas religiosas tradicionales ligadas al catolicismo y al evangelismo sustentan, en general, ideologías represivas, disciplinadoras y culpabilizadoras respecto al ejercicio de 
las sexualidades. No obstante, como señala José Manuel Morán Faúndes (2017), la política sexual sostenida desde los activismos religiosos conservadores -y desde los neoactivismos reaccionarios frente a las demandas feministas y LGTTBQI+no debe considerarse solo como un asunto de moralidad. Se trata, principalmente, de un asunto de poder, porque lo que se encuentra constantemente en disputa es el control político de los cuerpos y el ordenamiento normativo que por siglos se edificó sobre dicha moral, y cuyo sentido de verdad absoluta se pone en entredicho.

En Latinoamérica, dichas religiones, especialmente el catolicismo y algunas iglesias evangélicas, han defendido cierto orden político y moral, constituyéndose en un elemento problemático y obstaculizador en relación con la ampliación de los derechos de las mujeres en cuanto a su autonomía sexual y al deslinde entre la sexualidad y la reproducción (Vuola, 2006; Felitti \& Gutiérrez-Martínez, 2015). Como señala Juan Marco Vaggione (2016), este orden en alianza con otras élites poderosas influye en la delimitación de los lineamientos básicos en materia legal y de políticas públicas. Por un sofisticado proceso de imbricación entre derecho secular y doctrina católica, «el derecho secular "transmuta" las normas religiosas en normas sociales, la familia católica en familia nacional y el pecado en delito» (Vaggione, 2016, p. 28).

$\mathrm{El}$ androcentrismo, la regulación heteropatriarcal y la vinculación de las mujeres y de lo femenino con lo doméstico y con lo reproductivo operan como factor común en las disposiciones religiosas (Morán Faúndes, 2017). En consonancia con ello, se condena toda sexualidad que se desligue de la función reproductiva y del marco conyugal-familiar, sobre todo para las mujeres. Nayla Vacarezza (2013) muestra cómo a través de un desplazamiento de significados, el catolicismo presenta al aborto como un "crimen contra la vida», a su legalización como un "genocidio» y estigmatiza a las mujeres que abortan como asesinas y como pecadoras. Esto genera un discurso polarizado entre «cultura de la vida» y "cultura de la muerte», y ubica en esta última las demandas de autonomía reproductiva históricamente promovidas desde los feminismos (Fuentes Belgrave, 2013). Este antagonismo irreconciliable entre cultura de la muerte y del mal versus cultura de la vida y del bien se encuentra explícitamente planteado en Evangelium Vitae (1995) junto con el llamado a los integrantes de la comunidad creyente a sentirse y a verse «implicados y obligados a participar, con la responsabilidad ineludible de elegir incondicionalmente en favor de la vida» (citado en Vaggione, 2012, p. 63). En otras palabras, un llamado a apegarse sin poner condiciones ni cuestionamientos frente 
a lo que la enseñanza oficial entiende por vida, que para el caso de los procesos de gestación está centrado en el producto mismo y no en las mujeres o en las personas que gestan.

En la disputa por sentidos discursivos, es de destacar que las estrategias del discurso oficial católico y evangélico se van sofisticando para lograr y para mantener mayor legitimación sin trastocar sus bases. Esta doble vara con la que se mide la vida abstracta y la vida concreta fue clara en el marco del debate social y legislativo en torno al proyecto de Ley de Interrupción Voluntaria del Embarazo (IVE), en 2018. ${ }^{2}$ Los discursos de los sectores contrarios a la legalización de la IVE intentaban mostrar aprecio por la vida de las mujeres y no solo por la potencial vida del producto de la gestación mediante el slogan «Salvemos las dos vidas». Sin embargo, y al mismo tiempo, se posicionaban de modo inflexible en cuanto a apoyar la modificación de las condiciones legales y sanitarias en que las mujeres y otras personas con capacidad de gestar abortan, cuyo efecto criminalizador afecta gravemente sus vidas y su salud integral.

A su vez, la demonización del aborto es el corolario de la sacralización de la maternidad, diseñada como destino único e ineludible de la Mujer en el sistema patriarcal de representaciones de género. El mito Mujer=Madre implica la sacralización de la maternidad, y la apelación a lo instintivo y a lo natural en las mujeres y su relación con la maternidad (Fernández, 2016). Por lo cual, las mujeres que abortan estarían transgrediendo las expectativas sociales dominantes sobre la supuesta naturaleza del ser mujer y son susceptibles de ser consideradas egoístas, irresponsables, descorazonadas, además de asesinas. Estas cualidades quedan acentuadas y confirmadas por las políticas que criminalizan el aborto voluntario (Zamberlin, 2015) y que actúan retroalimentándose de las normas religiosas (Fuentes Belgrave, 2013). De este modo, en países como la Argentina donde el Código Penal de 1921 tipifica al aborto voluntario como delito contra la vida, lo que es pecado para algunos sectores creyentes se impone como delito para toda la ciudadanía.

Este marco normativo moral, social y legal que carga negativamente al aborto con significaciones de culpa, de pecado y de muerte influye en las construcciones que las mujeres hacen sobre sus propias experiencias de aborto, a la vez que propicia la aparición de efectos psíquicos que, en gran medida, conciernen a estrategias biopolíticas de control y de disciplinamiento (Fernández \& Tajer, 2006). 
Sin embargo, y a pesar de este interjuego complejo entre lo religioso, lo legal y los dispositivos de género hegemónicos, la diversidad de vivencias sobre lo religioso da cuenta de una pluralidad que en quienes son creyentes se traduce en experiencias sobre la sexualidad que no necesariamente se ligan a sentimientos de culpa (Johnson, 2018).

Si bien las significaciones negativas sobre el aborto que construyen la Iglesia Católica y evangelista se presentan como pensamiento único posible (pecado / crimen), la vivencia de la religiosidad popular presenta una diversidad que se aleja o que reformula aquellos mandatos y valores religiosos hegemónicos, de modo que en las experiencias estos no actúan de manera inmutable y unívoca (Vuola, 2006). Los discursos promovidos por la jerarquía eclesiástica no son obedecidos tal cual por toda la comunidad de creyentes. El fenómeno denominado pluralización de lo religioso posibilita entender que dentro del espectro creyente existen discursos y prácticas heterogéneas y permite comprender algunos entrecruzamientos complejos entre prácticas sexuales e identificaciones religiosas (Vaggione, 2014).

Esta complejidad se vincula, también, con los cambios en las formas de creer, asociadas a la creciente autonomía de una religiosidad cada vez más alejada de las instituciones (Johnson, 2018). Fortunato Mallimaci (2015) denomina cuentapropismo religioso a los fenómenos asociados a creyentes sin iglesias, personas con desapegos institucionales que igualmente se sienten parte de una tradición religiosa, o a los distanciamientos relativos de los mandatos de las cúpulas de la organización religiosa con la que sienten una ligazón (Mallimaci, 2015, en Morello \& Rabbia, 2019).

De esta manera, nos aproximamos a la complejidad propia del vínculo entre aborto y religiosidad, que supera ampliamente el enunciado de que la religiosidad de las personas se asocia per se a un rechazo hacia las prácticas de aborto. La completa revisión bibliográfica elaborada por Morán Faúndes (2015) sobre publicaciones científicas realizadas en América Latina, entre 2009 y 2014, en torno al tema aborto e iglesias, muestra que hay una diversidad de formas en las que la identidad confesional modela las actitudes, las opiniones y las prácticas relacionadas con el aborto. En sus conclusiones, el autor marca la necesidad de profundizar en las conexiones entre los sentidos de la religiosidad y las prácticas del aborto, haciendo hincapié en los significados otorgados por las personas y diferenciando los tipos de aborto. El aborto farmacológico, a pesar de ser una opción de especial importancia 
en función de las carencias legales y sanitarias para cubrir esta demanda en Latinoamérica, habría sido poco investigado en sus particularidades (Morán Faundés, 2015).

Diferentes autoras que han abordado las experiencias de aborto en contextos legalmente restrictivos, nos permiten delimitar tres grandes ideas en torno a la religiosidad. Las mujeres que significan el aborto como asesinato y como crimen son aquellas que están más apegadas a los discursos católicos y experimentan mayor sufrimiento psíquico al decidir abortar, lo que se traduce en autorreproches, en sentimientos de culpa y en ser «malas mujeres» (López Gómez \& Carril Berro, 2010). Otras, en el camino de sobrellevar la propia decisión de abortar, buscan crear un entendimiento alternativo sobre un dios que perdona (Vuola, 2006). Y así como hay mujeres que después de abortar se apegan más a la doctrina religiosa y a la institución, otras reelaboran la presencia de dios como independiente de la iglesia, lo cual contribuye a la desculpabilización. En ocasiones, incluso, logran politizar la experiencia y deconstruir la idea doctrinaria de vida. Todo lo cual da cuenta de la complejidad en las negociaciones subjetivas entre la religiosidad y la experiencia de abortar (Johnson, 2018).

Considerando las significaciones hegemónicas religiosas entrecruzadas con otras circunstancias y sentidos - principalmente, del orden de lo legal y de los mandatos de género sobre la sexualidad femenina-, así como la pluralidad de maneras posibles de vivir las experiencias de aborto, nos preguntamos: ¿cómo actúan las creencias religiosas personales y la visión de dios en las tramitaciones emocionales de la experiencia de aborto en las mujeres entrevistadas? A partir de los relatos, atenderemos al despliegue de significaciones y de emocionalidades en torno a los propios abortos, sus legalidades y sus legitimidades, las maternidades y la sexualidad femenina. Consideraremos sus maneras particulares de sostener, de problematizar y de integrar dichas creencias en relación con la propia experiencia de aborto.

\section{Aspectos metodológicos}

La metodología es de tipo cualitativa con un diseño exploratorio e intensivo. A través del método biográfico, entramos en contacto con los relatos de mujeres que versan sobre sus propias experiencias de abortos, mayormente farmacológicos 
y realizados en sus domicilios. Dichos relatos implican el despliegue de la experiencia vivida en función de una selección de recuerdos y de su interpretación mediada por experiencias posteriores. Es decir, las entrevistadas no solo describen, también seleccionan, evalúan e interpretan (Lomsky-Feder, 1995, en Sautú, 1999). Nuestro interés se centra en estas interpretaciones y/o versiones de la propia experiencia, que se construyen desde las creencias, las inquietudes y los valores individuales que sostiene la persona, a la vez que se entrelazan y se enraízan en un determinado contexto histórico-social (Sautú, 1999; Vieytes, 2004).

Como herramienta para interiorizarnos en el estudio de la religiosidad, nos parece interesante el enfoque de la religión vivida, planteado por Gustavo Morello y por Hugo Rabbia (2019). Este enfoque explora la religiosidad «de abajo hacia arriba», a partir de entender que no existen modos predeterminados de vivir la religión ni acatamientos pasivos de las normas provenientes de organizaciones religiosas tradicionales. Asimismo, atiende a los modos en que las personas dan sentido a sus vidas y a las experiencias que la conforman, tomando elementos religiosos como seculares y poniendo de relieve la propia capacidad de agencia de quienes cohabitan con «seres extraordinarios y fuerzas trascendentes en las que se apoyan, que las acompañan, con quienes dialogan o con quienes libran un combate permanente» (Morello \& Rabbia, 2019, p. 16).

Esta perspectiva sociológica se interesa, además, por los efectos que la creencia tiene sobre la vida de las personas y de las sociedades, a la vez que entiende que las transformaciones sociosubjetivas afectan la religiosidad de las personas. En este sentido, si bien nuestro interés se focaliza en el papel de la religiosidad en la experiencia emocional de aborto, observaremos los diversos caminos que las creencias religiosas adoptaron en la trayectoria vital de las mujeres entrevistadas, en función de haber atravesado la experiencia de aborto en un determinado contexto y de un modo particular.

En el marco de la investigación, durante 2017 y 2019 entrevistamos a un total de 30 mujeres, cuyo contacto iniciamos referenciadas por activistas feministas o a partir de nuestras propias prácticas de acompañamiento a mujeres que abortaron en las provincias de San Luis y de Mendoza, y, luego, mediante el muestreo en bola de nieve, a partir del cual una entrevistada proponía a otra cuya experiencia se correspondiera con los criterios de inclusión establecidos para la muestra. Estos criterios contemplaban haber abortado farmacológicamente, al menos una vez 
y dentro del recorte témporo-espacial establecido, es decir, que los abortos hubiesen ocurrido en las provincias de San Luis o de Mendoza, de 2010 en adelante.

Las entrevistas en profundidad se realizaron a partir de un guión flexible basado en grandes tópicos sobre la experiencia de aborto (Vieytes, 2004). Tuvieron una duración de entre 50 y 150 minutos, y fueron grabadas con el consentimiento de las entrevistadas. Luego de su transcripción, realizamos una primera codificación inductiva. En este primer análisis, emergió el eje vinculado a la religiosidad, centrado en los relatos sobre aspectos y sobre creencias religiosas en relación con las experiencias de aborto voluntario clandestinizado, sus significaciones y sus emocionalidades.

Del total de entrevistas realizadas durante la investigación, para este artículo tomamos cinco relatos de quienes expresaron estar cercanas desde la creencia y/o la práctica a una religión al momento de abortar; tres mujeres se autodefinieron como creyentes no practicantes y dos como creyentes practicantes. Las religiones en cuestión fueron el catolicismo y el evangelismo. Los nombres fueron modificados para respetar el criterio de confidencialidad y de preservación del anonimato, acordado de manera previa a la realización de las entrevistas [Tabla 1].

\begin{tabular}{|c|c|c|c|c|}
\hline Entrevistada & $\begin{array}{c}\text { Ejercicio } \\
\text { de la religiosidad }\end{array}$ & Religión & & $\begin{array}{l}\text { Edad/año en que } \\
\text { realizó el aborto }\end{array}$ \\
\hline Eva & Creyente practicante & Evangelista & (CP/E) & 25 años, 2017 \\
\hline Guadalupe & Creyente practicante & Católica & $(\mathrm{CP} / \mathrm{C})$ & 40 años, 2017 \\
\hline Bárbara & $\begin{array}{c}\text { Creyente } \\
\text { no practicante }\end{array}$ & Católica & $(\mathrm{CnP} / \mathrm{C})$ & $\begin{array}{l}23 \text { años, } 2005 \\
33 \text { años, } 2015\end{array}$ \\
\hline Anahí & $\begin{array}{c}\text { Creyente } \\
\text { no practicante }\end{array}$ & Católica & $(\mathrm{CnP} / \mathrm{C})$ & 22 años, 2017 \\
\hline Marisa & $\begin{array}{c}\text { Creyente } \\
\text { no practicante }\end{array}$ & Evangelista & (CnP/E) & $\begin{array}{l}22 \text { años, } 2016 \\
25 \text { años, } 2019\end{array}$ \\
\hline
\end{tabular}

Tabla 1 | Caracterización de las entrevistadas Fuente: elaboración propia 
Religiosidad y experiencias emocionales de aborto:

significaciones y resignificaciones

\section{La creencia religiosa y la visión de dios \\ como organizadores de sentido del propio aborto}

En los relatos seleccionados, algunas de las entrevistadas reconocieron el peso que tuvieron sus creencias religiosas en la experiencia emocional de aborto que atravesaron. Muchas de ellas se refirieron a este proceso en términos de conflicto, es decir, aludieron a la notable incompatibilidad entre la decisión / acción de abortar y la propia creencia religiosa, frente a la cual emprendieron diversas negociaciones subjetivas.

Tanto para Guadalupe como para Eva la religión se presentó como un significativo organizador de sentidos respecto de las emocionalidades asociadas a la experiencia. Ambas se autodefinieron como creyentes y como practicantes e iniciaron su relato haciendo un recorrido por las diversas instituciones y espacios de socialización religiosa temprana, que incluyeron la familia, la escuela y la comunidad de creyentes. En reiteradas ocasiones, enfatizaron que sus creencias religiosas fueron determinantes, tanto al momento de asumir la decisión como en la configuración emocional posterior al aborto, incluso, pasado más de un año.

\footnotetext{
Soy cristiana. En un momento esa fue la cuestión que me afectó emocionalmente, porque soy cristiana católica y practicante, desde chica.

(...) Practicante, sí. Ese tema fue puntual, puntual, porque una está muy marcada por los principios morales, religiosos... Por todo lo que uno tiene desde la familia, cultural, me costó mucho (Guadalupe, CP/C).
}

Su decisión no fue un paso simple ni ajeno a las contradicciones, por un lado, entre sus creencias y los valores morales que una "parte» de ella sostenían, y que conceptualizó como "un chip que tenés grabado» y, por otro, frente a la evaluación y al reconocimiento de su necesidad de interrumpir un embarazo sentido como sorpresivo e inoportuno. 
Sentir la culpa, decir: «Soy yo la que estoy decidiendo, porque es mi situación. No quiero vivir una situación parecida, no quiero pasar por otro momento de necesidad muy grande». Y desde lo católico decía: «Pero ¿cómo? Si no está bien, es un pecado mortal. Dios se va a vengar de lo que yo estoy haciendo, decidiendo». Es como que la culpa empieza a trabajar, pero pensé: «No, pongo en una balanza...» y pude hacerlo, gracias a Dios, ponerlo en la balanza y decidir, porque puntualmente yo no quería tener otro bebé, otro hijo (Guadalupe, $\mathrm{CP} / \mathrm{C}$ ).

En este sentido, resulta interesante el concepto de moralidad de la situación, de Rosalind Petchesky (1986, citada por Rostagnol, 2016), que alude a la compleja negociación que las mujeres que interrumpen voluntariamente sus embarazos realizan entre la ideología, la realidad social y el deseo, al tomar la decisión. En el relato de Guadalupe, queda en evidencia que los sentimientos de culpa y el miedo al castigo por cometer «un pecado mortal» (su ideología religiosa) cargaron el tránsito por la experiencia. Pero en esta negociación interna tuvo mayor peso la evaluación sobre la imposibilidad sentida de asumir una nueva maternidad. Esta imposibilidad se basó en los costos y en las dificultades que había sobrellevado en sus experiencias previas de maternidad, las cuales se dieron en el marco de una relación de pareja violenta y en soledad, con una sobrecarga de responsabilidades (su realidad). Asimismo, desempeñó un papel importante la idea de que las decisiones sobre su vida le pertenecían y necesitaban acomodarse a su deseo actual (deseo).

Eva inició la entrevista reafirmando su identidad evangelista y su fe en dios, a la vez que señaló una distancia respecto de la institución y de la comunidad religiosa tras abortar. El sentirse potencialmente juzgada y señalada afectó su religiosidad:

Soy evangélica. Mi papá es católico y mi mamá es evangélica. Creo en Dios, creo en Dios y ahora... He abierto mucho más mi cabeza, mi mente. (...) Ahora no creo mucho en la Iglesia. Por todo, todas las cosas que pasan, la gente que más te juzga es la que más cree que está haciendo el bien, pero es la que primero te apunta y te juzga... Soy muy creyente de Dios, tengo 
mucha fe en Él, siempre le agradezco por todo y siempre me ha ido bien, es por la fe que tengo. Pero la Iglesia, hasta por ahí nomás, no he vuelto a frecuentar ninguna Iglesia. Pero bueno, tengo mi creencia y mis padres, que son también creyentes. Sí, soy evangélica, soy evangélica (Eva, CP/E).

Al igual que Guadalupe, Eva hizo referencia a la culpa ligada a sus creencias religiosas sobre el aborto como un asesinato y un acto reprobable, cercano a lo demoníaco; una completa transgresión tanto a los principios de su religión como a los mandatos de género incorporados a lo largo de su proceso de socialización, fuertemente influido por la comunidad religiosa de pertenencia.

Fue una lucha contra mis creencias, mis ideales, mis valores.... Una lucha con todo... Antes, por todas mis creencias, creía que [el aborto] era un asesinato, en pocas palabras. Que era algo muy malo, extremadamente malo y por eso estuve tan mal. Sentía mucha culpa, bastante culpa, demasiada... (Eva, CP/E).

El relato de su estado emocional al momento de realizar el aborto en su casa es duro y tortuoso. Utilizó la medicación en soledad y en secreto, dudando, llorando, sintiendo que merecía el dolor físico que experimentó durante la expulsión del saco gestacional, soñando con el «feto muerto» y pidiendo perdón, según expresó, a «Dios, su hijito y su madre». Se sentía mala, asesina e inmoral.

Toda esa noche lloré bastante porque sentía que había matado a alguien.

Esa era mi sensación y que iba en contra de todos los valores y de todo lo que se me había inculcado (Eva, CP/E).

Las concepciones que sostenía sobre el aborto, acorde a los valores religiosos inculcados, impregnaron de sentimientos negativos la decisión y la experiencia posterior. En su sentido de la moral, había una división tajante entre personas buenas y malas en función de sus actos. Al aplicar esta lógica sobre sí misma, a partir de realizar una acción concreta considerada como extremadamente mala, y por lo tanto reprochable, su identidad quedó eclipsada bajo esa acción, bajo la 
lógica según la cual: hice algo malo, soy mala, merezco castigo. Abortar constituía, además, la primera desobediencia a los mandatos familiares y socioculturales de género aprendidos y acatados, ya que Eva se autodefinía como una mujer sumisa, muy obediente a sus papás y sin pensamientos propios. Su relato sobre los malestares a lo largo del proceso de aborto farmacológico se corresponden con la posibilidad de que la propia creencia religiosa se constituya en un peso para el tránsito emocional por la experiencia (López Gómez \& Carril Berro, 2010).

Posteriormente al aborto, sostuvo autorreproches rumiantes, sentimiento de culpa y una actitud de autocastigo; en sus palabras, de "echar sal a la herida" mediante el recuerdo insistente y detallado de ese momento. A la vez, relató la necesidad de evadir el tema sin poder escuchar ni mencionar la palabra aborto públicamente, que era como mencionar al «demonio». También fue notable la preocupación y el malestar por una posible estigmatización desde el afuera, que por mucho tiempo la llevaron a mantener un silencio aturdidor sobre la propia experiencia.

$\mathrm{Ni}$ siquiera podía escuchar la palabra, ni siquiera. Nada. Como que hablaban de aborto, o algo así, y me perseguía, me tenía que ir o algo... Fue tremendo... No lo podía hablar, no lo podía ni siquiera mencionar.

Siempre busqué la aprobación de alguien más... Entonces al estar mal visto por muchas personas, no quería saber que yo lo había hecho. Ni siquiera escuchar la palabra, me escapaba, me iba... Fue tremendo (Eva, CP/E).

El relato de Eva se asemeja a lo que Nina Zamberlin (2015) registra como estigma percibido, esto es, aquella apreciación individual acerca de lo que los demás piensan sobre el aborto y de las terribles consecuencias que podría tener que la experiencia propia tomara estado público. El estigma sobre el aborto no es algo natural sino político, es decir, depende de mecanismos de poder diferenciales que han llevado a su construcción y a su normalización. El estigma asociado al aborto emerge y acciona en distintos niveles, entre los que figuran los individuos, las comunidades, las instituciones, las estructuras de gobierno y los discursos en general. 
A nivel individual, el estigma implica un impacto emocional y psicológico que se expresa en sentimientos de malestar, de vergüenza y de culpa. El sentirse avergonzada y moralmente cuestionable aumenta la vulnerabilidad a sufrir estrés psicológico. Es interesante pensar cómo la consideración descontextualizada de las implicancias emocionales del estigma que ha sido normalizado se utiliza como fundamento para la patologización del aborto bajo el supuesto síndrome postaborto, sin identificar su origen, justamente, en la vivencia estigmatizada (Kumar, Hessini \& Mitchell, 2009, citado en Zamberlin, 2015). En este sentido, la experiencia de Eva resulta clarificadora para pensar tanto en el proceso de construcción de la culpa y del malestar como en los procesos saludables que conlleva el desarmar esas culpas asociadas a modos particulares en los que se significa el propio aborto, lo cual retomaremos en el último apartado de este trabajo.

Bárbara, otra entrevistada, compartió el relato de dos abortos. En cuanto al momento vital en el que ocurrió el primero - diez años antes de la entrevista-, expresó haber tenido una formación religiosa católica que, hasta ese entonces, no había cuestionado. En aquel momento de su vida se autodefinía como una mujer sin cercanía a la Iglesia en tanto institución, pero medianamente influida por preceptos religiosos que actuaron como una pesada carga culpógena. A pesar de expresar que «había una parte que sí, pero había otra parte que no creía tanto», reconoció vivirlo con «una carga catolicucha», en tanto «estructura que cuesta desarmar en estas instancias», debido a su influencia católica temprana. Sus opiniones y sus concepciones morales previas sobre el aborto y sobre la sexualidad femenina ubicaban al aborto como una elección de las «malas mujeres» y al embarazo como ligado, indiscutiblemente, a una maternidad.

\footnotetext{
Esta cuestión de «bueno, si abriste las piernas, báncatela». Toda esta cuestión de que si las mujeres no podíamos elegir esto, no podíamos elegir el aborto, porque si lo elegías eras una mala mujer. Este discurso que está extendido... Mendoza es bastante retrógrada en algunas cosas y «catolicucha». De alguna manera, una crece escuchando esas cosas. Así que tenía, más que una opinión propia, esos prejuicios (Bárbara, $\mathrm{CnP} / \mathrm{C})$.
} 
En las experiencias relatadas, las creencias y los valores religiosos coexistieron con otros múltiples organizadores de sentidos y de circunstancias que dieron lugar a configuraciones emocionales diversas y complejas. En el relato de Bárbara, su configuración emocional estuvo marcada no solo por los valores morales católicos y conservadores sobre el aborto, sino sobre lo que la sexualidad femenina debía ser. Relató, además, un sufrimiento acentuado por la forma en la que este primer aborto ocurrió: una situación de intervención quirúrgica cargada de violencias en una clínica clandestina donde recibió un trato desubjetivizante por parte del médico. Los sentimientos asociados a la clandestinidad de la práctica médica quirúrgica, descripta como «horrible; muy denigrante; un momento doloroso y angustiante», contribuyeron al sentimiento de autocriminalización; en sus palabras, a "sentir que era terrible lo que estaba haciendo». Esta vivencia reforzó lo malo, lo incorrecto y lo denigrante de abortar.

\footnotetext{
Realmente, es como que te sentís una criminal, por la forma en que te levantás y por la forma en que pasa ahí. (...) Me sentía como si hubiera hecho, jcometido un delito! Todo muy oscuro... La misma situación es muy horrible (Bárbara, CnP/C).
}

Sin embargo, el relato sobre su segundo aborto, que fue farmacológico y con asesoramiento de una organización feminista, da cuenta de una configuración emocional distinta que le permitió rescatar aspectos saludables ligados al modo de abortar. En sus palabras, tras este segundo aborto:

La sensación después del proceso fue de fortaleza. Fue de sentir que una misma puede hacer cosas por sí misma, por su propia salud. Y que otras mujeres nos pueden acompañar y que no es necesario estar tirada en un colchón, hecha mierda, con médicos que te dicen cómo tenés que llamar a lo que te estás haciendo vos, ¿no? ¡Con mucha autonomía! (Bárbara, CnP/C).

El relato de Bárbara sobre ambos abortos, y sobre sus condiciones, resulta interesante para observar las transformaciones y las diferencias en sus configuraciones emocionales. Estas diferencias pueden pensarse en función de 
múltiples variables, donde las creencias morales religiosas, en caso de estar vigentes, se despliegan y se entretejen con otras múltiples variables. En el primer aborto, destacamos dos: la ausencia de una reflexión crítica sobre ciertas concepciones morales y religiosas ligadas al aborto, y a la sexualidad que sostenía, y el modo en que se realizó el aborto. La experiencia de aborto quirúrgico se asocia a la impronta de la ilegalidad debido a la presencia de una mirada ajena y dotada de autoridad que la observa y la juzga por algo que ella también significa como incorrecto o reprochable. Diferente al aborto farmacológico practicado en su hogar, con las compañías elegidas y tras haber realizado un proceso de reflexión sobre algunas significaciones vinculadas al aborto, propio y en general, que abordaremos en el último apartado de este escrito.

El relato de Marisa difiere de los anteriores en tanto no manifestó un reconocimiento expreso de la influencia de su religiosidad. Aprehendemos dicho papel por la correspondencia entre las significaciones que construyó sobre sus experiencias y los valores morales que trenzan embarazo con vida/hijo. Los dos embarazos que interrumpió de manera farmacológica fueron significados como hijos o bebés y sobre el aborto opinó:

¿Del aborto? Sí, tenía la opinión de que no, que eso estaba mal. Decía: «Cómo van a abortar si ya está. Si te quedaste, ya está, tenelo, porque es una vida que vas a interrumpir».

(...) Son mis hijos, yo ahora tendría cuatro hijos (Marisa, CnP/E).

Marisa relató interrumpir vidas y abortar hijos, lo cual vivió con ambivalencias, dudas y autorreproches. Además, refirió una convivencia entre el alivio de no tener más hijxs -que no se sentía en condiciones de maternar y que afectarían la crianza de sus hijas pequeñas- y la culpa por haber abortado.

Cuando lo hicimos, cuando yo lo hice, sentí mucho alivio. Estaba bien, feliz. Sentí mucho alivio y pensé: «Ya está, voy a seguir criando a la Amalita, así se llama la chiquitita, bien». Me empecé a cuidar y está todo bien. Pero es 
feo, porque después sentís una culpa de decir: «¿Qué es lo que hice? Eso está mal». Yo me sentí mal y estuve mucho tiempo... angustiada, como deprimida. No comía, claro, porque me sentía culpable. (...) Después te queda una culpa, un remordimiento y después que pasó todo decís: «¿Por qué lo hice? ¿Y si lo hubiera tenido?» (Marisa, CnP/E).

Según lo expuesto, las significaciones vinculadas con creencias religiosas, más allá de su reconocimiento o no, operaron a partir de conflictuar la experiencia y aportaron a experimentar malestares emocionales que se expresaron, principalmente, bajo la forma de culpa y de autorreproches. Pero también encontramos relatos de mujeres creyentes en los que la culpa y los autorreproches no aparecieron, y primó el alivio y la autoafirmación de la decisión como correcta. Son estas disimilitudes las que dan cuenta de la multiplicidad de vinculaciones que pueden darse entre aborto y religiosidad.

En el relato de Anahí, quien se autodefinió como creyente católica no practicante ni cercana a la institución Iglesia, la creencia religiosa no aparece como un organizador principal de sentidos. De acuerdo a su relato, no manifestó un conflicto entre la creencia en dios y el acto de abortar ni experimentó sentimientos de culpa. Tampoco el autodefinirse como creyente adquirió un papel significativo al momento de decidir, pues esta decisión se basó en considerar que continuar ese embarazo implicaría una interrupción en el proyecto educativo en curso que con tanto esfuerzo había emprendido, así como también en evaluar su realidad socioeconómica y el sentimiento de no estar preparada para afrontar una crianza que, a su entender, «no es solo darle cariño».

$\mathrm{Su}$ decisión estuvo apoyada en circunstancias vitales ligadas a condiciones socioeconómicas y al diseño de un proyecto de vida que le permitiría mejorar su situación, a partir de pensar en la posibilidad de ascenso social mediante los estudios universitarios y el futuro trabajo profesional. Todo esto le brindó el marco subjetivo necesario para concretar el aborto sin ambivalencias, dudas, arrepentimientos ni autorreproches, tanto a lo largo del proceso de aborto como en el tiempo posterior. En términos de moralidad de la situación, podemos pensar que 
el resultado de la negociación entre ideología, realidad social y deseo fue más armónica y sin costos emocionales elevados, a diferencia de lo que se desprende de los relatos anteriores (Petchesky, 1986, citada por Rostagnol, 2016).

En esta situación, interesa señalar dos cuestiones: por un lado, su visión del papel de Dios, en quien creía fervientemente junto con la Virgen; por otro, su grado de distanciamiento con las estructuras institucionales del catolicismo o del cuentapropismo religioso (Mallimaci, 2015, en Morello \& Rabbia, 2019), ya que si bien se autodefinía como católica creyente reconoció no participar activamente de los ritos eclesiásticos institucionales ni sentirse cercana a una comunidad de creyentes, como sí ocurría en el caso de Eva o de Guadalupe al momento de abortar. $\mathrm{Al}$ hacer referencia a su religiosidad, Anahí diferenció con claridad y marcó una distancia entre el plano de los valores sostenidos por la Iglesia (lo que la Iglesia sostiene) y el de las necesidades concretas, las realidades socioeconómicas y las propias experiencias (la realidad que ella vive). En este sentido, eligió hacer primar su autoridad por sobre la autoridad religiosa, dando cuenta de una mayor autonomía de conciencia y de un distanciamiento.

No, la verdad que no [no interfirieron las creencias religiosas]. No, porque soy católica pero tampoco es que voy a misa siempre y, además de eso, hay una realidad que es la que yo vivo. O sea, si bien creo en Dios y en la Virgen, pero tampoco la Iglesia... Dios sí, siempre está con nosotros, nos ayuda, pero como que uno también tiene su propia situación y como que la mía, económicamente... Creo que, es más que todo, por eso. $\mathrm{Y}$, además, porque no estaba preparada, no era la mejor [situación]. Sé bien, obviamente, siempre supe lo que la Iglesia piensa sobre eso pero...

Creo que, desde un principio, yo no estaba tan afectada, no estaba afectada por lo que iba a hacer, porque como era mi decisión, digamos, es como que no estaba afectada, no me sentía emocionalmente mal. Me sentía rara y, también, aliviada porque había salido bien... (Anahí, CnP/C).

El relato de Anahí muestra cómo la situación fue atravesada sin implicancias emocionales negativas en cuanto a la práctica en sí misma. Los malestares relatados se centraron en el momento previo al aborto, principalmente, la desesperación por no conseguir ayuda, la incomodidad por tener que ocultar el embarazo ante familiares 
y los temores a no poder abortar por interposición de otras personas en su decisión. También, si la medicación fallaba, por el miedo a tener un «bebé» con malformaciones físicas. Todo lo cual, en gran medida, se vincula con las condiciones legales y sociales de restricción de la práctica, que afectan, a su vez, la garantía de realizarla de manera segura, cuidada y efectiva.

En cuanto a su visión de dios, no se desprende de su relato la idea de un ser castigador, sino de una presencia que está dispuesta a ayudar, y que, en su caso, comprende los motivos para abortar. Se trata, también, de un vínculo no mediado por la iglesia ni por los valores hegemónicos de dicha institución. Este tipo de visión, la de un dios que acompaña, tranquilizó y facilitó la tramitación emocional de la experiencia en condiciones adversas.

En otros relatos, encontramos que la construcción de la visión de dios que realizan las mujeres creyentes en tanto ente supervisor omnipresente de esta situación vital también jugó un papel relevante en el tránsito emocional por la experiencia.

Guadalupe se refirió a un dios sentido como vengativo, lo cual propició temores y fantasías de castigo. Durante la entrevista, sostenida a más de un año del aborto, reiteró sentimientos -temporarios- de culpa y de miedo ante las posibles represalias de dios, lo cual coexistía tensa y dificultosamente con el alivio de haber resuelto el embarazo no deseado e inoportuno.

Por eso, la decisión fue tomada y dije: ¡Hoy, me siento tranquila! Pero si te tengo que decir la verdad, hay momentos en los que emocionalmente tengo esa sensación de que me mandé algo... Que hice algo que no corresponde, feo...

Ahora, pasado más de un año, hay veces que se vuelven a cruzar emociones. En momentos puntuales, se me cruzan las emociones de la culpa. Sí, la culpa y el miedo a que, si en algún momento va a tomar... ¡Mirá, lo que es la locura! O no sé si es locura... Si dios en algún momento va a hacer algo con mis hijos (Guadalupe, (CP/C).

Eva, por su parte, a más de un año del aborto, agradeció a dios este obstáculo que tuvo que afrontar, ya que implicó una oportunidad subjetiva para desarmar, para cuestionar y para rearmar sus valores y sus creencias, lo cual continuaba haciendo 
al momento de la entrevista. En el proceso posterior al aborto, su visión de dios era de protección y de acompañamiento, presencia que le brindó la fuerza necesaria para salir fortalecida de las adversidades. También vivenció protecciones divinas para realizar ese recorrido sin morir en el intento:

(...) Pero, después, no sé qué fue lo que dio el vuelco en mi vida que lo usé como un escalón para poder subir. Lo usé como un escalón y la verdad es que por mi creencia, por mi religión, yo agradezco a Dios que haya pasado todo esto, porque no lo hacés de mala mina, ¿me entendés? No lo hacés porque sos una mujer sin valores, porque sos... Son cosas que te tocan vivir en el momento.

(...) Tengo muchos ángeles que me presentaban las personas en el instante correcto, porque si no hubiera tenido ninguna orientación, si lo hubiera hecho de distinta manera, en un quirófano clandestino, que me hubiera muerto... (Eva, (CP/E).

Hasta aquí, hemos profundizado en ciertos modos en los que las creencias religiosas y la visión que se construye sobre dios modelan y regulan las significaciones y las emocionalidades sobre la propia de experiencia de aborto. En el siguiente apartado, veremos que estas regulaciones y estas afectaciones no necesariamente permanecen fijas e inamovibles. Por el contrario, la actuación de procesos de resignificación puede transformar tanto las emocionalidades en torno a la experiencia como la religiosidad misma.

Procesos de resignificación de las experiencias:

la culpa también se puede desarmar

Cuando intentamos comprender las configuraciones emocionales que giran en torno a las situaciones de embarazo no deseado / aborto voluntario, atendemos con igual importancia las complejidades previas a la práctica como el recuerdo del aborto en sí y los procesos posteriores. En ocasiones, estos últimos habilitan profundas resignificaciones de la experiencia encarnada. Entendemos que toda esta secuencia, tal como señala Susana Rostagnol (2016), no ocurre en abstracto, sino que es indisoluble de las condiciones y las circunstancias en que acontecen. Comprenden 
un proceso total y dinámico, en el que las personas gestantes que abortan se acercan o se alejan de diversos discursos, del orden de lo secular y/o de lo religioso, lo que les permite narrar sus experiencias de aborto y darles diversos sentidos.

En algunos de los relatos en los que las creencias religiosas actuaron con efectos culpógenos, registramos diferentes recorridos donde se pudieron matizar las significaciones y las emocionalidades negativas, al entrar en contacto comprometido con otros discursos. En el caso de Bárbara y de Eva, la posibilidad de resignificar la decisión y/o la experiencia en un espacio psicoterapéutico colaboró en la disminución de la carga culpógena, de los autorreproches y del estigma percibido. Además, ambas mencionaron, para distintos momentos de la experiencia y con distinto nivel de compromiso subjetivo, la influencia que tuvo el haber estado en contacto con discursos feministas que significan el aborto como un derecho y lo despojan de su carácter de inadecuado o de incorrecto.

Bárbara necesitó desarmar y rearmar la trama de significaciones y la configuración emocional respecto al aborto, la maternidad y el embarazo con ayuda de su terapeuta, al momento de consolidar la decisión de su primer aborto y posteriormente la práctica. En este proceso, pudo repensar e incorporar elementos ligados al deseo y a la distinción entre la condición biológica y la condición subjetiva deseante, entre el deseo de tener un/a hijo/a y el hecho biológico de haber estado embarazada.

[La psicóloga ayudó] para no sentir culpa con la decisión. Me parece fundamental entender que no todo embarazo es siempre deseado y que no siempre tenés que continuar el embarazo si no querés. Para mí, era todo un tema tomar la decisión, sentir lo que estaba haciendo, que si estaba bien o mal, porque hay una cuestión moral también. Fue la que ayudó a sacarme la carga más moralista, más esto de la cuestión católica de la culpa, del asesinato de un ser vivo, de toda esa cuestión (Bárbara, $\mathrm{CnP} / \mathrm{C})$.

Aliviada de la carga proveniente de la culpa asociada a una moral católica, comenzó a resignificar su propio aborto desde otros posicionamientos. En el transcurso de su trayectoria vital, sus significaciones experimentaron un cambio notable. Esto se evidenció en la configuración emocional de su segundo aborto que, además de ser 
farmacológico y con la presencia de personas de su confianza que le brindaron apoyo, ocurrió luego de haber realizado un proceso de politización del aborto desde miradas feministas. Esto la llevó a incorporarse activamente en la Campaña Nacional por el Derecho al Aborto Legal, Seguro y Gratuito, y a acompañar a otras mujeres desde su rol profesional. Es decir, no solo se alejó de los discursos morales religiosos sino que se acercó a discursos feministas que favorecieron el apropiarse de la experiencia y cargarla de emocionalidades y de sentidos más saludables.

$\mathrm{Su}$ segundo aborto fue narrado como una experiencia totalmente opuesta a la primera, no sintió culpa ni angustia ni los efectos de la criminalización, a pesar de que el contexto socio-legal era bastante similar. "Sabía que era ilegal, pero no lo viví desde la ilegalidad», expresó. Interesa destacar, entonces, la transformación que se produjo en su configuración sobre aborto y en la posición subjetiva de legitimidad para decidir o, en términos de Marta Rosenberg (2020), en la institución subjetiva del aborto como derecho. A lo cual se suma, como señalábamos, cómo los modos en los que se aborta interceden en los modos de experimentar las legalidades y las legitimidades de la decisión y del acto de interrumpir un embarazo. Su segundo aborto fue una práctica autogestionada y sin presencia médica, que protagonizó acompañada de personas emocionalmente significativas y elegidas (la mayoría de las cuales pertenecían a grupos feministas). Todo ello puede pensarse en contraposición al sentimiento de cosificación impotente que sintió durante el aborto quirúrgico. Fue una experiencia «muy distinta porque es autónoma, 100\% autónoma», describió.

Eva también rescató el contacto con discursos feministas que le permitieron suavizar sus significaciones sobre aborto y sobre ella misma como "mala mujer». A partir del acompañamiento de una socorrista, expresó:
(...) sentí mucha seguridad y apoyo en Celeste [socorrista]. Antes, para mí, lo que yo iba a hacer era matar a un ser. Pero ella me explicó todo: «Es así, es asá». ¡Yo necesitaba que alguien me dijera lo contrario! Con ella yo vi que lo iba a poder sobrellevar más, que lo que estaba haciendo no era, no tenía una magnitud tan grande como yo creía (Eva, CP/E).

Meses después de abortar, Eva comenzó un espacio terapéutico para abordar el malestar emocional que sentía. Allí, pudo problematizar aspectos de su vida y de su identidad como mujer, que si bien abarcaban la situación de aborto también la 
excedían. Dejó de hostigarse por su decisión y de autoestigmatizarse, al resignificar este evento en función de su historia personal y familiar, y de reconocer los atravesamientos culturales y religiosos presentes en su trayecto vital.

Descubrí que mi problema estaba más enraizado con cosas pasadas de mi familia, de la sumisión, de lo que me habían hecho creer antes, de la falta de toma de decisiones propias y salió un montón de culpa...

(...) de cómo he salido, me siento orgullosa de eso. En otro momento, no te hubiera podido decir lo mismo, pero ahora sí (Eva, CP/E).

En este proceso de desarmar la culpa y de reconocerse en sus fortalezas al atravesar una situación crítica, Eva relató haber realizado un cuestionamiento profundo a los modelos de género inculcados en su familia y a los valores morales de su religión. A partir de que pudo ir diferenciándose progresivamente de aquellos mandatos familiares / culturales / religiosos que no eran coherentes con sus necesidades, sus deseos y sus visiones fue modificando los sentimientos negativos hacia ella misma.

A la vez, esta experiencia ocasionó en su religiosidad algunas modificaciones que pueden vislumbrarse en el relato. Su creencia religiosa en dios se mantuvo e, incluso, los sentimientos de comprensión y de guía estuvieron presentes en sus significaciones sobre cómo fue atravesando la experiencia de aborto, lo que afianzó su vínculo personal con dios y una visión positiva del mismo. Sin embargo, cesó de participar y de asistir a la iglesia, a la vez que dejó de sentir a la comunidad de creyentes como un posible grupo de apoyo, al ubicarlos como «la gente que más te juzga». Este apoyo sí fue experimentado desde los grupos feministas que la acompañaron, específicamente mediante la presencia de la socorrista y de una amiga feminista que la acercó a este grupo local.

\section{Consideraciones finales}

A partir de los relatos sobre experiencias de abortos de las entrevistadas, advertimos que tanto las creencias religiosas como la visión que construyen de su 
dios marcan la experiencia emocional. Si bien algunas configuraciones emocionales priman por sobre otras, existe cierta diversidad entre las experiencias relatadas y los procesos de transformación al interior de una misma experiencia.

En primer lugar, las mujeres reconocen que las creencias religiosas y los valores morales asociados conflictúan la decisión y la tramitación emocional del propio aborto. Los preceptos religiosos tradicionales y sus discursos de verdad impregnan sus significaciones sobre aborto como asesinato y como acto reprochable, lo cual propicia culpa, autorreproches y malestar emocional. Pero las vivencias culpabilizantes no son exclusivas; también encontramos un relato de una mujer que se autopercibía como creyente donde dichas creencias no adquirieron un peso significativo ni propiciaron una afectación emocional negativa. Interesa destacar las complejas negociaciones que las mujeres emprenden entre sus creencias, la evaluación de su realidad actual y el registro de su condición deseante en torno al eje embarazo / maternidad.

En segundo lugar, la visión de dios y las cualidades que se le adscriben también juegan un papel significativo en la configuración emocional de la experiencia. De modo que un dios sentido como vengativo propicia temores al castigo, en contraposición a un dios sentido como comprensivo y acompañante que genera tranquilidad y sensación de protección. A pesar de esta marcada polaridad, interesa destacar el abanico de posibilidades que esta figura puede adquirir en el proceso de aborto de mujeres creyentes: ayudar en la toma de una decisión necesaria para ese momento de la vida, allanar el camino para conseguir los recursos y las orientaciones para abortar en un contexto adverso, ser el receptor de los pedidos de perdón. Cada mujer, cada persona, más allá de lo que la institución indique, podrá agenciar su visión de dios y el vínculo que establece con esta figura en los distintos momentos del proceso de abortar y de tramitar emocionalmente esta experiencia.

En tercer lugar, las configuraciones emocionales culpógenas, cuando están presentes, no necesariamente son fijas e inamovibles sino que pueden verse modificadas por otros organizadores de sentidos. Muchos de ellos se construyen y se interiorizan durante los procesos posteriores de tramitación emocional de la experiencia. Algunas mujeres, en sus recorridos para tramitar el aborto voluntario, encontraron en los discursos feministas, en los procesos de politización del aborto y en los espacios psicoterapéuticos despojados de connotaciones estigmatizantes, nuevos sentidos para configurar la experiencia y sus emocionalidades. En este 
camino, hay quienes problematizaron hasta abandonar dichas creencias religiosas y quienes, a partir del cuestionamiento, modificaron su vínculo con la institución iglesia, distanciándose.

Los procesos relatados nos permiten entender que las creencias religiosas coexisten de manera más o menos tensa con variadas circunstancias y organizadores de sentidos en las configuraciones emocionales de las experiencias de abortos clandestinizados. Los sentidos vinculados a mandatos de género heteropatriarcales y/o al discurso jurídico criminalizador, con sus correspondientes alianzas a nivel social, contribuyeron a engrosar, para algunas creyentes, los malestares ya experimentados. Sin embargo, el encuentro con discursos feministas activistas y/o con discursos que las mujeres construyeron en espacios psicoterapéuticos donde se pudo poner en valor la propia condición deseante e inscribir los malestares en tramas vitales sociosubjetivas de género y culturales más amplias y complejas, tuvieron efectos desculpabilizadores y/o matizaron la culpa sentida.

Por último, se advierte que el tránsito emocional por la experiencia de aborto generó modificaciones en la religiosidad que permitieron problematizar los malestares experimentados. Así como las significaciones religiosas que se sostienen son un ordenador importante sobre cómo se vive emocionalmente; la experiencia $\mathrm{y}$ sus devenires permiten poner en cuestionamiento y revisar muchas de las creencias que entran en conflicto con las necesidades advertidas, en este caso, la de interrumpir un embarazo en curso.

Las creencias religiosas, morales y políticas judeo-cristianas constituyen un organizador de sentido relevante que no opera exclusivamente para quienes profesan expresamente una religión, sino que, en su carácter hegemónico, impregnan diversas manifestaciones y sentires sociales y subjetivos. Develar estos sentidos, que actúan explícita o solapadamente organizando las experiencias vinculadas a la sexualidad y a los cuerpos de las mujeres y de otras personas con capacidad de gestar y de abortar, ayuda a comprender cómo se construyen y se deconstruyen las cargas valorativas sobre dichas experiencias y cómo se entrelazan con los malestares y los alivios sentidos. De este modo, sería interesante indagar a futuro cómo operan dichas creencias religiosas y morales en las experiencias de personas que abortaron y que no se autodefinen como creyentes pero que, sin embargo, se encuentran atravesadas por marcos normativos de este y de otros órdenes. 
Agradecimiento: A Cecilia Johnson, por sus recomendaciones y sus orientaciones en la construcción de estas reflexiones.

\section{Referencias}

Carril Berro, E. y López Gómez, A. (2008). Entre el alivio y el dolor.

Mujeres, aborto voluntario y subjetividad. Montevideo, Uruguay: Trilce.

Felitti, K. y Gutiérrez-Martínez, D. (2015). Envites entre diversidades, sexualidades y creencias. La necesidad de un libro más. En K. Felitti y D. Gutiérrez-Martínez (Coords.), Diversidades, sexualidades y creencias: cuerpo y derechos en el mundo contemporáneo (pp. 9-38). Ciudad Autónoma de Buenos Aires, Argentina: Prometeo y El Colegio Mexiquense.

Fernández, A. M. y Tajer, D. (2006). El aborto y sus significaciones imaginarias: dispositivos políticos sobre los cuerpos. En S. Checa (Comp.). Realidades y coyunturas del aborto: entre el derecho y la necesidad (pp. 33-46). Ciudad Autónoma de Buenos Aires, Argentina: Paidós.

Fernández, A. M. (2016). La mujer de la ilusión. Pactos y contratos entre hombres y mujeres. Ciudad Autónoma de Buenos Aires, Argentina: Paidós.

Foucault, M. (1979). Microfísica del poder (Edición y traducción Julia Varela y Fernando Alvarez-Uría). Madrid, España: de la Piqueta.

Fuentes Belgrave, L. (2013). Afirmar la autonomía reproductiva en la disidencia religiosa. Iconos. Revista de Ciencias Sociales, (45), 59-74. https://doi.org/10.17141/iconos.45.2013.3108

Johnson, M. (2018). «Ni la pareja, ni la familia, ni la Iglesia deciden por mí». La experiencia del aborto en mujeres católicas. Sexualidad, Salud y Sociedad, (28), 51-70. 
López Gómez, A. y Carril Berro, E. (2010). Aborto voluntario y subjetividad en contextos de penalización. Efectos y significados en mujeres, varones y profesionales de la salud. Psicología, Conocimiento y Sociedad, 1(2), 1-36. Recuperado de https://revista.psico.edu.uy/index.php/revpsicologia/article/view/40

Morán Faundés, J. M. (2015). Aborto e iglesias. Cuatro focos analíticos en América Latina. En S. Ramos (Comp.), Investigación sobre aborto en América Latina y El Caribe: una agenda renovada para informar políticas públicas e incidencia (pp. 95-128). Ciudad Autónoma de Buenos Aires, Argentina: CEDES; Ciudad de México, México: Population Council; Lima, Perú: Promsex.

Morán Faúndes, J. M. (2017). Desafíos post-seculares: intersecciones entre religión y sexualidad en el escenario global contemporáneo. En medicusmundi gipuzkoa: Encuentros Donostia 2017. Impacto de los fundamentalismos políticos, económicos, religiosos y culturales en los derechos sexuales y reproductivos (pp. 151-173). San Sebastián, España: medicusmundi gipuzkoa. Recuperado de https://www.academia.edu/37746220/Desaf\%C3\%ADos_postseculares_intersecciones_entre_religi\%C3\%B3n_y_sexualidad_en_el_esc enario_global_contempor\%C3\%A1neo

Morello, G. y Rabbia H. (2019). Introducción. En H. Rabbia, G. Morello, N. Da Cota y G. Romero (Comps.), La religión como experiencia cotidiana: creencias, prácticas y narrativas espirituales en Sudamérica (pp. 9-32). Córdoba, Argentina: Editorial de la Universidad Católica de Córdoba / Fondo Editorial Pontificia Universidad Católica del Perú / Universidad Católica del Uruguay.

Rosenberg, M. (2020). Escuchar las demandas, instituir la subjetivación del derecho al aborto. En AA.VV., El derecho al aborto en la formación "psi”. Tensiones, demandas y desafíos (pp. 41-51). Ciudad Autónoma de Buenos Aires, Argentina: Teseo. 
Rostagnol, S. (2016). Aborto voluntario y relaciones de género.

Políticas del cuerpo y de la reproducción. Montevideo, Uruguay:

Ediciones Universitarias UdelaR.

Sanseviero, R. (2003). Condena, tolerancia y negación. El aborto en Uruguay. Montevideo, Uruguay: Frontera.

Sautú, R. (1999). Estilos y prácticas de la investigación biográfica.

En Sautú, R. (Comp.), El método biográfico. La reconstrucción

de la sociedad a partir del testimonio de los actores (pp. 21-60).

Ciudad Autónoma de Buenos Aires, Argentina: Editorial de Belgrano.

Vacarezza, N. (2013). Política de los afectos, tecnologías de visualización y usos del terror en los discursos de los grupos contrarios a la legalización del aborto. En AA.VV., El aborto como derecho de las mujeres. Otra historia es posible (pp. 209-226). Ciudad Autónoma de Buenos Aires, Argentina: Herramienta.

Vaggione, J. M. (2012). La «cultura de la vida». Desplazamientos estratégicos del activismo católico conservador frente a los derechos sexuales y reproductivos. Religião e Sociedade, 32(2), 57-80.

Recuperado de https://doi.org/10.1590/S0100-85872012000200004

Vaggione, J. M. (2014). La politización de la sexualidad y los sentidos de lo religioso. Sociedad y Religión, XXIV(42), 209-226. Recuperado de http://www.redalyc.org/articulo.oa?id=387239045010

Vaggione, J. M. (2016). Sexualidad, derecho y religión: entramados en tensión. En M. Sáez y J. Morán Faúndes (Eds.), Sexo, delitos y pecados. Intersecciones entre religión, género, sexualidad y el derecho en América Latina (pp. 18-52). Washington, Estados Unidos: American University.

Vieytes, R. (2004). Metodología de la investigación en las organizaciones, mercado y sociedad: epistemología y técnicas. Ciudad Autónoma de Buenos Aires, Argentina: De las ciencias. 
Vuola, E. (2006). ¿Gravemente perjudicial para su salud? Religión, feminismo y sexualidad en América Latina y el Caribe. Pasos, (127), 15-26. Recuperado de http://bibliotecavirtual.clacso.org.ar/Costa_Rica/dei/20120712012320/gra vemente.pdf

Zamberlin, N. (2015). Estigma y aborto. El estigma asociado al aborto como objeto de estudio: los primeros pasos en América Latina.

En S. Ramos (Comp.), Investigación sobre aborto en América Latina y El Caribe. Una agenda renovada para informar políticas públicas e incidencia, 31(3), 833-860. Recuperado de http://www.scielo.org.mx/scielo.php?script=sci_arttext\&pid=S0186$72102016000300833 \& \operatorname{lng}=$ es\&tlng=es

\section{Notas}

1 Financiamiento: Consejo Nacional de Investigaciones Científicas y Técnicas (CONICET) mediante Beca Doctoral a la Mtra. Natalia Santarelli para el desarrollo de la tesis doctoral en Estudios de Género (Universidad Nacional de Córdoba): «Las significaciones que las mujeres construyen en torno a sus experiencias de abortar con medicamentos en relación con la salud mental. Análisis desde una perspectiva de género en la región de Cuyo a partir de 2010». Trabajo de tesis dirigido por la Dra. Claudia Anzorena.

2 Este artículo fue escrito previamente al cambio legislativo en torno a la Interrupción Voluntaria del Embarazo en la Argentina. En 2020, el Poder Ejecutivo se comprometió a presentar un proyecto de ley que fue debatido y aprobado en diciembre de ese año, y que entró en vigencia en enero de 2021 como Ley 27.610 de Acceso a la Interrupción Voluntaria del Embarazo. 